\title{
The effect of rail travel time on airline fares: first evidence from the Italian passenger market."
}

\author{
Claudia Capozza ${ }^{\dagger}$
}

\begin{abstract}
The empirical evidence shows that travel time is crucial for rail transport to be a competitor to air transport. However, there are no papers testing whether travel time has a direct effect on airline pricing. This paper is a step towards filling this gap. We test and quantify the effect of rail travel time on airline fares, using unique data at flight-level. We find that airlines design pricing strategies taking into consideration the travel time of competing rail transport service. Airlines are found to set, on average, higher fares as rail travel time increases. However, the competitive pressure induced by rail travel time is perceived by airlines only as the day of departure gets closer: from the $30^{\text {th }}$ to the day before departure it increases while it gradually decreases as the departure date gets further away.
\end{abstract}

Key words: airline fares, rail travel time, inter-modal competition.

JEL: L11, L13, L93

\footnotetext{
* The author is very grateful to Prof. Angela S. Bergantino for insightful comments and valuable discussions. All remaining errors are the author's.

${ }^{\dagger}$ University of Bari "Aldo Moro", email: claudia.capozza@uniba.it.
} 


\section{Introduction}

The development of high-speed rail (HSR) network - on which trains can exceed the speed of $250 \mathrm{~km} / \mathrm{h}^{1}$ - has fostered the competition between air and rail transport by reducing the difference in point-to-point travelling time. As long as trains become faster, rail transport becomes a substitute to air transport, as shown in Figure 1. Competition between HSR and airlines is stronger on the short-medium haul. In fact, door-to-door journey time is lower for HSR than air travel from $150 \mathrm{~km}$ distance. As distance increases, the difference narrows and door-to-door journey times converge to $800 \mathrm{~km}$ distance. From this distance onwards, air transport steadily gains ground with respect to HSR. Differently, conventional rail journey time is far greater than air transport already from $400 \mathrm{~km}$ distance.

Figure 1. Traditional rail, HSR and air transport: a comparison.

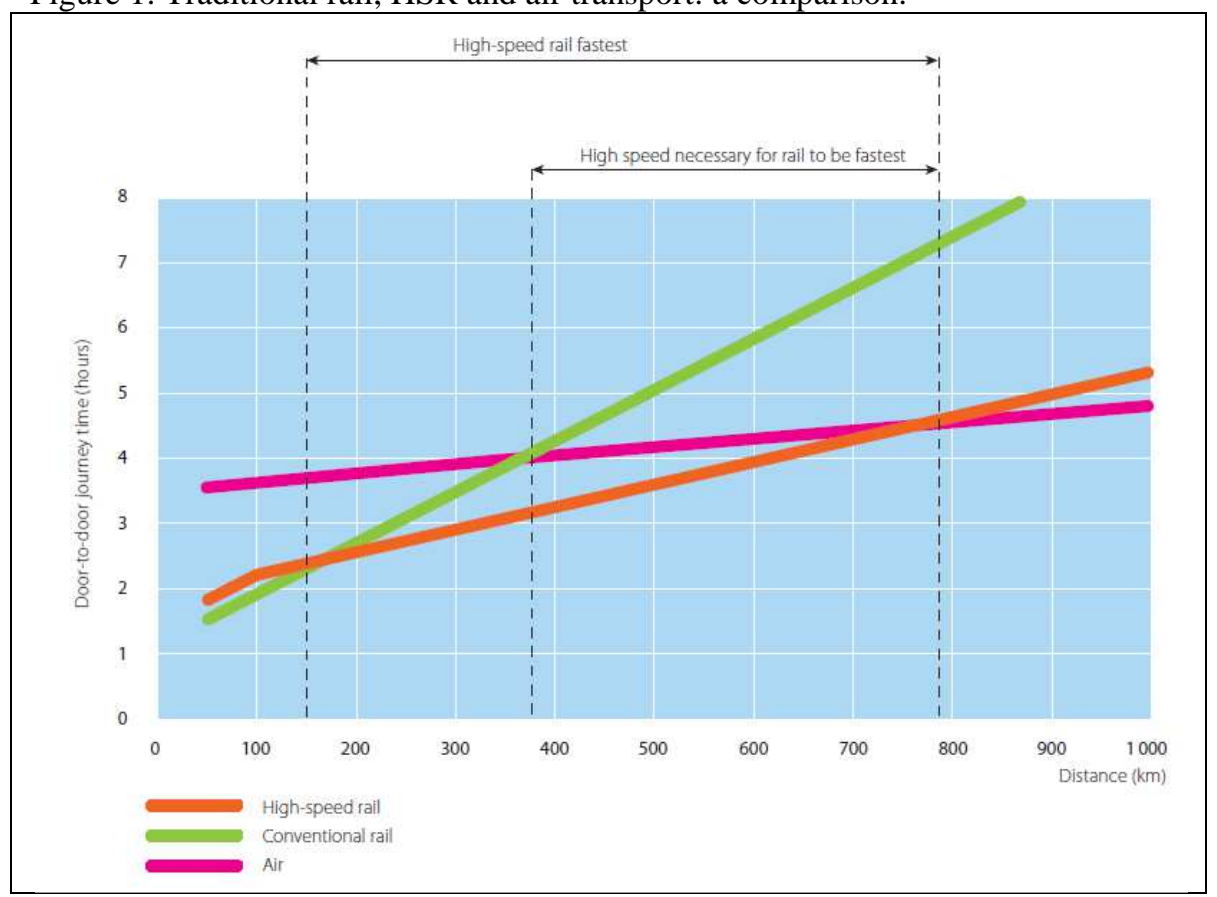

Source: European Commission (2010).

Some empirical papers studying the modal choice and the level of substitutability between air and rail transport modes emphasise the importance of travel time for rail transport to be a fierce competitor to air transport. González-Savignat (2004) analyses the potential of HSR to compete with air transport on the Madrid-Barcelona line by the means of experimental design techniques. The impact of HSR on airline market is found to be rather important because a

\footnotetext{
${ }^{1}$ As established by the Union Internationale de Chemin de Fer (2010).
} 
significant part of the transport demand is diverted to HSR depending on travel time. As travel time increases, HSR loses a substantial market share. Also Dobruszkes (2011) recognises that HSR travel time is a key competitive factor, together with the elements influencing the waiting time or the access time and, as a result, the total journey time. ${ }^{2}$ Using the stated preference (SP) approach, Behrens and Pels (2012) study travellers' behaviour in the London-Paris market and the conditions under which HSR becomes a viable alternative to air transport. Among the results, HSR market share appears to be influenced by the total travel time (as well as by the frequency and fare). As long as the total travel time decreases, rail market share increases at the expenses of air market share, but the increment is higher for the business segment whose passengers are more time sensitive than leisure passengers.

In this paper we investigate the price effect of competition between rail and air transport. Despite the evidence shows that the rail travel time is crucial in the competition between rail and air transport, to our knowledge, there are no empirical papers testing whether it has a direct effect on airline pricing. In a theoretical model, Yang and Zhang (2012) demonstrate that airline fares are decreasing in rail speed, supporting this finding by numerical simulations. In a complementary fashion, we, thus, design an empirical model to estimate the relationship between rail travel time and airline fares, using real data at flight-level. Particularly, we aim at understanding whether airlines plan their pricing strategies - the level and the dynamics - taking into consideration the travel time of the competing rail transport service.

Our work contributes to the stream of research on the inter-modal competition between air and rail transport which have shown that the two markets are strictly connected, and that there are significant effects on demand and supply. Park and Ha (2006), using the SP approach, show that the opening of HSR line in South Korea exerts a significant competitive pressure on airlines, leading to a decline of air transport demand. Similarly, Fu et al. (2012) observe that in the short-medium haul Chinese market, HSR transport is driving airlines' company yields down and diverting traffic from air to rail. Betancor and Jiménez (2012) examine air carriers' reaction to the opening of HSR services in Spain. They test whether HSR affects airline travel frequencies and market shares, and they find that the presence of HSR service reduce, on average, the number of air operations by $17 \%$, although the Spanish flag carrier does not seem to be affected by HSR competition. More recently, Bergantino et al. (forthcoming) focusing on the Rome-Milan line find that airlines significantly reduce fares when flights are in direct

\footnotetext{
${ }^{2}$ The analysis considers five European city-pairs: Paris-Metz, Paris-Brussels, Brussels-London, Paris-Marseilles, and Cologne-Munich.
} 
competition with HSR services. Albalate et al. (2014) study the impact of HSR services on air traffic (frequencies and seats) at route level, focusing on connections between cities in large European countries. ${ }^{3}$ Interestingly, results show that airlines competing with HSR services reduce the number of seats offered on a given route, although the flight frequencies do not undergo a major reduction. It seems that airlines take on the strategy of keeping flight frequencies high even though their demand has fallen. The reduction of services is greater at hub airports. However, hub airports having on-site HSR station experience a smaller reduction of air services than hub airports that do not have it. This highlights the potential for cooperation between the two means of transport.

Some papers focus on the effects of HSR infrastructure provision. Using a game theoretical approach, Adler et al. (2010) explore the competition between HSR and air transport on the medium-long haul. Results suggest that the European Union should encourage the investments in upgrading to HSR infrastructure across Europe, in order to stimulate travellers to move from air to rail transport and foster the inter-modal competition. Martin and Nombela (2007) explore the microeconomic impacts from planned investments in infrastructures in terms of changes of individuals' choice of transport modes on Spanish domestic lines. They find that, if the rail infrastructure is upgraded for HSR running, for long-distance routes the HSR transport will attract the demand of air and bus passengers, while for shorter routes HSR transport will mostly capture car users' demand. Finally, Bergantino and Capozza (2014), exploring Italian domestic routes, show the indirect benefits that investments to improve rail infrastructure would yield through a curbing effect on competing airline fares.

In this paper, we study the impact of rail travel time on airline pricing strategies with an empirical analysis focused on the Italian passenger market. A shown in Figure 2, the Italian market is particularly suited for the purpose of this paper since the speed at which train can run on the network is heterogeneous in the country.

\footnotetext{
${ }^{3}$ Four countries in the European Union: France, Germany, Italy and Spain.
} 
Figure 2. High speed rail network in Italy

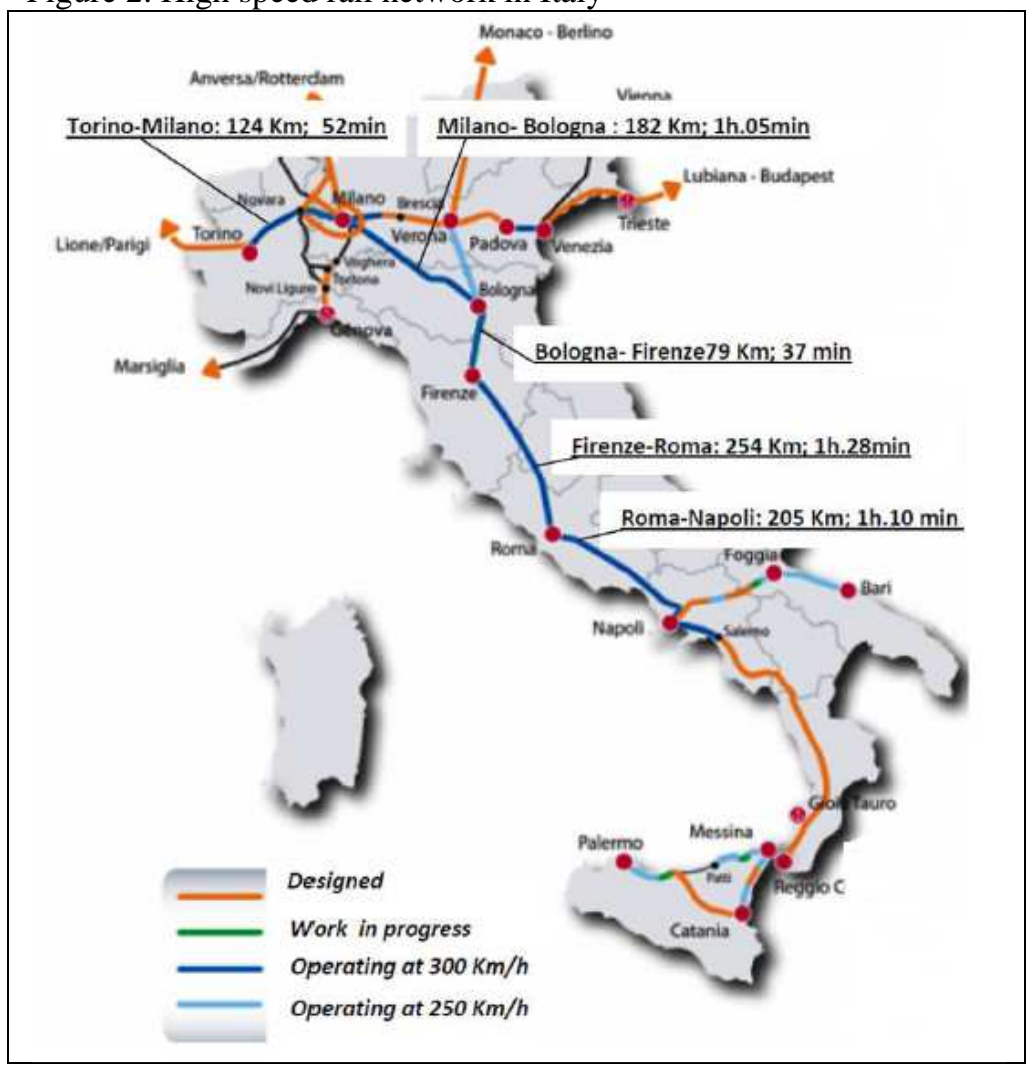

Source: Cascetta and Coppola (2014)

High-speed lines depicted in blue - running trains at $300 \mathrm{~km} / \mathrm{h}$ - connect the cities on the Adriatic route. There are also some short parts of the network depicted in light blue, interspersed with conventional lines, allowing trains to run at $250 \mathrm{~km} / \mathrm{h}$. Finally, the orange lines indentify the conventional network for which upgrading projects for running HSR services are planned, but not yet effective.

As well as contributing to explaining the competitive dynamics in the transport sector, the results of the analysis might provide relevant policy implications. Looking at Figure 2, it clearly emerges that North-Centre Italy has a higher quality railway infrastructure than South Italy, providing faster transport services and a greater set of choices available to people for travelling. If this translates into pricing policies by the airlines that leverage the lack of viable modal alternatives, the cost of accessibility would be passed on to weaker consumers.

We create an exclusive self collected database to accomplish the research objectives. First, we simulate the travellers' purchase process of round-trip tickets from the websites of airline companies. The simulation and fares' recording are carried out every single day, for each ticket, beginning sixty booking day preceding the departure date. Second, the data on the recorded fares are matched with the travel time of the competing rail service. The dataset we 
have constructed is, to our knowledge, the sole composed by fares at flight level, for each booking day and for all the airline companies that operate on the Italian city-pairs with representative geographical coverage.

The empirical results support our intuition that rail travel time has a direct impact on airline fares. As rail competitive pressure, measured by travel time, gets feebler, airlines become able to apply higher fares. On average, a 10\% increase in rail travel time allows airlines to increase fares up to $3.9 \%$. Moreover, the impact of rail travel is only effective as of 30 days before departure and it increases gradually as flight departure is closer in time.

The plan for the rest of the paper is as follows. In Section 2 we present the empirical strategy: we give a description of the database and we illustrate the empirical model. In Section 3 we discuss the results and in Section 4 we draw conclusions and policy implications.

\section{Empirical strategy}

\subsection{Data collection}

To carry out the empirical analysis we match data on airline fares at flight level with data on travel time required by the competing rail service.

To collect data on airline fares we simulate the travellers' purchase process of round-trip tickets from the websites of airline companies. ${ }^{4}$ The purchase simulation and fares' recording are done every single day, for each ticket, beginning the sixtieth booking day preceding the departure date. ${ }^{5}$ We record the basic ticket to have comparable fares among carriers.

The round trip flights can be attributed to the following time slots: Morning (6:00-10:00), Midday (10:00-14:00), Afternoon (14:00-18:00) and Evening (18:00-24:00). The sample contains 67 Italian domestic routes (the list is reported in Table 1 in the Appendix) and 7 airline companies: Airitaly, Alitalia-Airone, BluExpress, EasyJet, Meridiana, Ryanair, Volotea. The database has 17,235 observations on 360 round-trip flights from September to December 2012.

Data on rail travel time are retrieved from the official railway timetables that report departure and arrival time for each running train, hence it is possible to calculate the travel time. Each round-trip flight is linked to travel time of the fastest train that provides a service on the same

\footnotetext{
${ }^{4}$ Data on fares are retrieved directly from the companies' website to avoid potential distortions on pricing strategies caused by online travel agencies that could set discounted fares.

${ }^{5}$ For some round-trip flights we have less than sixty observed fares.
} 
city-pair, on the same couple of departure and return dates, and that reaches the station around the same time. For connections from/to the isles we also include the shipping travel time if no alternative modes are available.

Similarly, data on the number of flights are taken from the official airport schedules for computing market structure variables.

As mentioned above, to collect data on fares we simulate the purchase process of round-trip flights instead of one-way flights. This is done for several reasons. First, we more likely replicate the purchasing behaviour of travellers that generally buy a return ticket rather than a one-way tickets. ${ }^{6}$ Second, we accurately define the real travel alternatives. For a given couple of departure and return dates, we identify the number of flights operated by each competing airline and we use them for creating a more detailed measure of market structure. Third, looking at the date of departure and return, we determine if the flight is operated during holidays and we test the hypothesis that airlines set higher fares when the travel demand is greater. Finally, FSCs use to set a fare for round-trip flight which is lower than the sum of the two one-way fares corresponding to the same couple of departure and return dates. For this reason previous papers studying airline pricing with one-way fares focus the empirical analysis to LCCs or to a few carriers. Instead, we get rid of this issue, being able to compare fares across all carrier types.

\subsection{Model}

We define the following regression equations. The first equation estimates the average effect of rail travel time on airline fares. The second equation estimates the effect of rail travel time moderated by booking days in order to explore the temporal dynamics of the effect.

$$
\begin{aligned}
\ln \left(P_{\mathrm{ijkst}}\right)=\alpha & +\beta \ln R T T_{\mathrm{ijks}}+\gamma \cdot f B D_{\mathrm{t}}+\eta M S T R_{\mathrm{ijks}}+\theta H P E A K_{k s}+\lambda L C C_{k s} \\
& +\rho C T R L_{\mathrm{ijkst}}+u_{\mathrm{ijkst}} \\
\ln \left(P_{\mathrm{ijkst}}\right)=\alpha & +\beta \ln R T T_{\mathrm{ijks}}+\gamma \bullet f B D_{\mathrm{t}}+\delta(\ln R T T * B D)+\eta M S T R_{\mathrm{ijks}}+\theta H P E A K_{k s} \\
& +\lambda L C C_{k s}+\rho C T R L_{\mathrm{ijkst}}+u_{\mathrm{ijkst}}
\end{aligned}
$$

where $i$ indexes the route, $j$ the carrier, $k$ the departure date, and $s$ the return date. The daily time dimension $t$ goes from 1 to 60 .

\footnotetext{
${ }^{6}$ See Belobaba's (1987) study on the airline travel demand.
} 
The dependent variable is the logarithm of fares. The regressor of interest is the logarithm of rail travel time (lnRTT), defined as the travel time per kilometre - averaged between the two directions of the city-pair - of the fastest train that provides a service on the same city-pair, in the same departure/return dates, reaching the ending station around the same time of the corresponding flight. Our intuition is that, ceteris paribus, the greater the travel time required by the competing rail service, the lower the competitive pressure induced on airlines. We, thus, expect this variable to have a positive sign: a slower connection allows airline to set higher fares.

The variable booking day (BD) captures the effect of inter-temporal price discrimination and ranges from 1 to 60 . As suggested by previous empirical findings, ${ }^{7}$ the functional form of BD is non-monotonic, thus we also include its square among the regressors.

In the Equation (2), we add the interaction between $\ln (\mathrm{RTT})$ and BD to verify whether the effect of rail travel time increases or decreases as long as the departure approaches.

The airline market structure is measured by two indices: market share (MKTSH) and Herfindahl-Hirschman Index (HHI). The MKTSH is the number of the scheduled daily flights operated by an airline in a city-pair over the total number of scheduled daily flights operated by all the competing airlines in that city-pair, ${ }^{8}$ calculated as the average between the two directions of the city-pair. It follows that the HHI is $\sum_{j=1}^{N} \mathrm{MKTSH}_{\mathrm{ijks}}^{2}$.

The variable HPEAK is a peak-period dummy equal to 1 for flights operated during official Italian holidays, 0 otherwise. The variable LCC is equal to 1 for flights provided by LCCs, 0 otherwise.

The set of control variables (CTLR) includes route-specific dummies, capturing the routespecific effects, demand and cost (or price) differences; month dummies, controlling for seasonal effects; departure dummies and return dummies, two sets of four categorical dummies, capturing the effect of the time of takeoff $(6: 00-10: 00 ; 10: 00-14: 00 ; 14: 00-18: 00$ and 18:00-24:00) ${ }^{9}$ and, finally, dummies controlling for the trip length.

The composite error term $u_{\mathrm{ijkst}}$ is equal to $\alpha_{\mathrm{ijks}}+\varepsilon_{\mathrm{ijkst}}$, where $\alpha_{\mathrm{ijks}}$ is the unobserved heterogeneity and $\varepsilon_{\mathrm{ijkst}}$ is the idiosyncratic error term.

In our models some regressors, as the lnRTT, MKTSH or HHI take the same value along the time period (i.e. the sixty booking day). Basically, the travel time of the competing rail

\footnotetext{
${ }^{7}$ See Alderighi and Piga (2010), Gaggero (2010), Bergantino and Capozza (2014; 2015).

${ }^{8}$ Market structure variables are computed at city-pair level because almost all the carriers could operate as a monopolist on a given route. The city-pair level allows to capture the competition between carriers.

${ }^{9}$ See Gaggero and Piga (2011).
} 
services as well as the number of flight scheduled by the airlines are the same whether the traveller purchases the flight 60,30 or 10 days before departure. We consider the random effects generalised least square (RE-GLS) method to estimate the coefficients of timeinvariant variables. The RE-GLS estimator is based on the assumption of zero-correlation between explanatory variables and the unobserved heterogeneity $\alpha_{\mathrm{ijks}}$ to provide consistent estimates. The validity of this assumption is tested with the robustified Hausman test. ${ }^{10}$

A further econometric issue is that we assume the exogeneity of market structure in the short run, given the high entry barriers preventing new carriers from entering markets (see Stavins, 2001). Moreover, in the European Union countries the grandfather rights apply and assure to an airline that held and used a slot in a given year to hold and use that slot in the same season the following year. Finally, a previous contribution (Bergantino and Capozza, 2015), using a similar data structure, proves the exogeneity of market structure in the short-run. ${ }^{11}$

\section{Results}

The empirical results provide evidence that the rail travel time has an influence on airline fares. ${ }^{12}$ In Table 2, columns (1) and (2), we report the results of the estimations from the first regression equation. The coefficient of $\operatorname{lnRTT}$ is positive and highly significant across regressions. A $10 \%$ increase in travel time of the competing rail service allows airlines to increase fares by $3.1 \%$ to $3.9 \%$. As the competitive pressure induced by rail services weakens, airline companies set higher fares. We can affirm, thus, that the duration of the journey of the competing mode does matter.

The variable BD has a negative and highly significant coefficient, whilst the coefficient of $\mathrm{BD}^{2}$ is positive and highly significant. Basically, the effect on fares is negative until the turning point is reached, thereafter positive. Thus, the inter-temporal profile of fares is non-

\footnotetext{
${ }^{10}$ See Wooldridge (2002), pp. 290-91.

${ }^{11}$ The set of instruments used is based on Borenstein (1989).

${ }^{12}$ The results of the Robust Hausman test do not lead to reject the null hypothesis that the RE GLS estimator is consistent. We find support for that because we include in the regressions a rich set of control dummies that contributes to solve the omitted-variables problem. Moreover, the RE-GLS estimator converges to the Within Group estimator as $t$ goes to infinity. In our dataset $t$ is equal to 60 that can be fairly considered as infinity.
} 
monotonic and it can be approximated by a J-curve. ${ }^{13}$ We estimate that its turning point occurs in the interval of the $48^{\text {th }}$ to $52^{\text {nd }}$ of the days before departure. ${ }^{14}$

In columns (3) and (4) we report the results of the estimations from the second regression equation, which allows the effect of rail travel time to vary with the booking days.

Table 2. RE GLS estimations.

(1)

\begin{tabular}{|c|c|c|c|c|}
\hline & (1) & $(2)$ & (3) & (4) \\
\hline Ln RTT & $\begin{array}{c}0.3083 * * \\
(0.1284)\end{array}$ & $\begin{array}{c}0.3880 * * \\
(0.1524)\end{array}$ & $\begin{array}{c}0.3488 * * * \\
(0.1290)\end{array}$ & $\begin{array}{c}0.4280 * * * \\
(0.1523)\end{array}$ \\
\hline $\mathrm{BD}$ & $\begin{array}{c}-0.0290 * * * \\
(0.0015)\end{array}$ & $\begin{array}{c}-0.0290 * * * \\
(0.0015)\end{array}$ & $\begin{array}{c}-0.0211 * * * \\
(0.0039)\end{array}$ & $\begin{array}{c}-0.0211 * * * \\
(0.0039)\end{array}$ \\
\hline $\mathrm{BD}^{2}$ & $\begin{array}{c}0.0003 * * * \\
(0.0000)\end{array}$ & $\begin{array}{c}0.0003 * * * \\
(0.0000)\end{array}$ & $\begin{array}{c}0.0003 * * * \\
(0.0000)\end{array}$ & $\begin{array}{c}0.0003 * * * \\
(0.0000)\end{array}$ \\
\hline Ln RTT*BD & & & $\begin{array}{c}-0.0020 * * \\
(0.0009)\end{array}$ & $\begin{array}{c}-0.0020 * * \\
(0.0009)\end{array}$ \\
\hline MKTSH & $\begin{array}{c}0.0060 * * * \\
(0.0013)\end{array}$ & & $\begin{array}{c}0.0060 * * * \\
(0.0013)\end{array}$ & \\
\hline HHI & & $\begin{array}{l}0.0041 * * \\
(0.0021)\end{array}$ & & $\begin{array}{l}0.0041 * * \\
(0.0021)\end{array}$ \\
\hline HPEAK & $\begin{array}{c}0.2558 * * * \\
(0.0688)\end{array}$ & $\begin{array}{c}0.2573 * * * \\
(0.0695)\end{array}$ & $\begin{array}{c}0.2497 * * * \\
(0.0689)\end{array}$ & $\begin{array}{c}0.2512 * * * \\
(0.0696)\end{array}$ \\
\hline LCC & $\begin{array}{c}-0.3213 * * * \\
(0.0530) \\
\end{array}$ & $\begin{array}{c}-0.4982 * * * \\
(0.0381)\end{array}$ & $\begin{array}{c}-0.3225 * * * \\
(0.0529)\end{array}$ & $\begin{array}{c}-0.4991 * * * \\
(0.0381) \\
\end{array}$ \\
\hline \multicolumn{5}{|c|}{ Robust Hausman test } \\
\hline Statistics & 1.231 & 1.215 & 1.175 & 1.160 \\
\hline p-value & 0.541 & 0.545 & 0.759 & 0.763 \\
\hline Observations & 17,235 & 17,235 & 17,235 & 17,235 \\
\hline
\end{tabular}

Standard errors (in parentheses) are clustered at flight-level. The set of control variables (CTLR) is always included but coefficients are not reported. *** $\mathrm{p}<0.01, * * \mathrm{p}<0.05, * \mathrm{p}<0.10$.

The coefficient of the interaction variable LnRTT*BD is negative and highly significant. This finding would suggest that the positive effect of rail travel time reduces as the departure is further away in time. In other words, the competitive pressure from the railway services appears to be stronger in the days closer to the departure. We test the significance of the total

\footnotetext{
${ }^{13}$ Gaggero (2010) suggests that the inter-temporal profile of fares is non-monotonic as it reflects a pattern opposite to that of travellers' demand elasticity. Bergantino and Capozza (2015) claim that a higher fare for veryearly purchasers can be considered as a fee for risk-aversion but also as the evidence that airlines exploit consumer bounded rationality.

${ }^{14}$ The turning point is computed from regressions' results showed in column (1) and (2).
} 
marinal effect of LnRTT on fares, the sum of the direct impact $(\beta)$ and the indirect impact through BD $(\delta)$. For the sake of convenience, in Table 3 we report the total marginal effects of LnRTT at some values of BD together with the significance level. The columns (5) and (6) refer to the estimations reported in columns (3) and (4) in Table 2, respectively.

We find that the total marginal effect of LnRTT is significant starting from the $31^{\text {st }}$ day before departure.

\begin{tabular}{ccc} 
Table 3. The total marginal effect of LnRTT at values of BD on \\
fares (standard errors in parenthesis). \\
\hline BD & $(5)$ & $(6)$ \\
\hline \hline 1 & $0.3449 * * *$ & $0.4241^{* * *}$ \\
& $(0.1288)$ & $(0.1522)$ \\
5 & $0.3290^{* *}$ & $0.4082^{* * *}$ \\
& $(0.1283)$ & $(0.1520)$ \\
10 & $0.3090^{* *}$ & $0.3883^{* *}$ \\
& $(0.1283)$ & $(0.1523)$ \\
15 & $0.2892^{* *}$ & $0.3684^{* *}$ \\
& $(0.1290)$ & $(0.1531)$ \\
\hline \multirow{2}{*}{20} & $0.2693^{* *}$ & $0.3485^{* *}$ \\
& $(0.1303)$ & $(0.1545)$ \\
25 & $0.2494 * *$ & $0.3286^{* *}$ \\
& $(0.1323)$ & $(0.1564)$ \\
30 & $0.2296^{*}$ & $0.3087^{* *}$ \\
& $(0.1349)$ & $(0.1589)$ \\
35 & 0.2097 & $0.2888^{*}$ \\
& $(0.1381)$ & $(0.1619)$ \\
\hline 40 & 0.1898 & 0.2690 \\
& $(0.1418)$ & $(0.1653)$ \\
& 0.1700 & 0.2491 \\
& $(0.1461)$ & $(0.1692)$ \\
& 0.1500 & 0.2292 \\
& $(0.1508)$ & $(0.1735)$ \\
& 0.1103 & 0.1894 \\
& $(0.1614)$ & $(0.1833)$ \\
\hline \multirow{3}{*}{50} & & \\
& &
\end{tabular}

One day before the departure, a $10 \%$ increase in rail travel time allows the airlines to set $3.5 \%$ to $4.2 \%$ higher fares. The effect shrinks as the departure is further away in time. This gradual 
reduction stops at the $31^{\text {st }}$ day before departure. In fact, for the interval between 31 to 60 day before departure the total marginal effect is not significant.

Regarding the impact of the other explanatory variables, MKTSH and HHI have a positive and highly significant impact on fares. ${ }^{15}$ When the competition among airlines reduces, the market power becomes greater, then carriers post higher fares. Specifically, a 10\% increase in the MKTSH leads to $6 \%$ higher fares and a $10 \%$ increase in the HHI leads to $4.1 \%$ higher fares. The coefficient of HPEAK is positive and highly significant, suggesting that airline post about $25 \%$ higher fares during peak-periods than off-peak period. This result is due by the greater demand for travelling, that usually characterises holiday times, which is exploited by airlines. Finally, as one might expect, the coefficient of $L C C$ is negative and highly significant across regressions, providing evidence that LCCs usually apply up to 50\% lower fares than FSCs.

\section{Summary and concluding remarks}

In this paper we have explored the price effect of competition between HSR and air transport, taking a different perspective than the existing research. Despite travel time is widely recognised as crucial in the competition between the two means of transport, no previous work has empirically tested whether rail time travel has a real impact on airline pricing policies. This work has the objective of conducting an empirical investigation aiming at measuring such effect. To this end, we have built a unique and inimitable dataset on Italian passenger market, containing level-flight information on daily fares posted by the airlines and on rail travel time corresponding to a given flight. The empirical application on the Italian market is meaningful because this market is heterogeneous in terms of rail infrastructures endowment (high-speed versus conventional). This makes it particularly suitable to the objective of the research. We find airlines to feel the competition from rail services: air fares, in fact, are increasing in rail travel time. As the competing transport service becomes slower, airlines rise fares. In particular, we find that competition from rail services has a significant impact on the price of airlines from one month before flight departure.

The general conclusions of the paper are the following. First, it provides new insights in the behavioural strategies of the airline sector by introducing an innovative element in the empirical literature - rail travel time - to explain pricing behaviour of airline companies in

\footnotetext{
${ }^{15}$ This finding is consistent with Gaggero and Piga (2010) and Brueckner et al. (2013).
} 
relation to inter-modal competition. Second, the results acquire an added value if interpreted in the light of the infrastructural gap which characterises the Italian peninsula (north-south gap). The absence of viable and faster rail alternatives to air transport yields higher fares for a weaker group of consumers. Therefore, when considering the opportunity cost of investing in faster rail services in the more deprived areas of the country, policy makers should consider also its indirect effects in terms of stimulating inter-modal competition. 


\section{References}

1. Adler, N., Pels, E., and C. Nash. "High-speed rail and air transport competition: Game engineering as tool for cost-benefit analysis." Transportation Research Part B, 44(7), 2010, 812-833.

2. Albalate, D., Bel, G., and Fageda, X. "Competition and cooperation between high-speed rail and air transportation services in Europe", Journal of Transport Geography, Available online 2014.

3. Alderighi, M., and C.A. Piga. "On-line Booking and Revenue Management: Evidence from a Low-Cost Airline." Review of Economic Analysis, 2(3), 2010, 272-286.

4. Behrens, C., Pels, E. "Intermodal Competition in The London-Paris Passenger Market: High-Speed Rail and Air Transport." Journal of Urban Economics, 71(3), 2012, 278-288.

5. Belobaba, P. P."Air travel demand and airline seat inventory management." $\mathrm{PhD}$ dissertation, Massachusetts Institute of Technology, 1987.

6. Bergantino, A.S. and Capozza, C. "Airline Pricing Behavior under Limited Inter-modal Competition", Economic Inquiry, 53(1), 2015, 700-713.

7. Bergantino, A.S. and Capozza, C. "One price for all? The role of market captivity as price discrimination device. Evidence from the Italian city-pair markets." SIET Working paper, 2014.

8. Bergantino, A.S., Capozza, C. and Capurso, M. " The impact of open access on intra- and inter-modal rail competition. A national level analysis in Italy." Transport Policy, forthcoming.

9. Betancor, O. and Jiménez, J.L. " When trains go faster than planes: The strategic reaction of airlines in Spain." Transport Policy, 23, 2012, 34-41.

10. Borenstein, S. "Hubs and High Fares: Dominance and Market Power in the U.S. Airline Industry." RAND Journal of Economics, 20(3), 1989, 344-365.

11. Brueckner, J.K., D. Lee, and E.S. Singer. "Airline competition and domestic US airfares: A comprehensive reappraisal." Economics of Transportation, 2(1), 2013, 1-17.

12. Cascetta, E. and Coppola, P. "Models for strategic and operational planning of high-speed rail service with application to an empirical case study". XVI SIET Conference, 2014.

13. Dobruszkes, F. "High-speed rail and air transport competition in Western Europe: A supply-oriented perspective", Transport Policy, 18(6), 2011, pp. 870-879.

14. European Commission. High-Speed Europe. A sustainable link between citizens. Luxembourg: Publications Office of the European Union, 2010. 
15. Fu, X., Zhang, A. and Lei, Z. "Will China's airline industry survive the entry of highspeed rail?" Research in Transportation Economics, 35(1), 2012, 13-25.

16. Gaggero, A.A. Airline Pricing and Competition: the J-curve of airline fares. Lambert Academic Publishing, 2010.

17. Gaggero, A.A., and C.A. Piga. "Airline Market Power and Inter-temporal Price Dispersion." Journal of Industrial Economics, 59(4), 2011, 552-577.

18. Gaggero, A.A., and C.A. Piga. "Airline competition in the British Isles." Transportation Research Part E, 46(2), 2010, 270-279.

19. Gonzalez-Savignat, M. "Competition in air transport: the case of the high speed train." Journal of Transport Economics and Policy, 38(1), 2004, 77-108.

20. Martin, J.C. and G. Nombela. "Microeconomic impacts of investments in high speed trains in Spain." The Annals of Regional Science, 41(3), 2007, 715-733.

21. Park, Y. and H.K. Ha. "Analysis of the impact of high-speed railroad service on air transport demand." Transportation Research Part E, 42(2), 2006, 95-104.

22. Stavins, J. (2001) "Price Discrimination in the Airline Market: The Effect of Market Concentration", The Review of Economics and Statistics, 83(1), pp. 200-202.

23. Union Internationale de Chemin de Fer. High-speed and the city, Paris, 2010.

24. Wooldridge, J. M. Econometric Analysis of Cross Section and Panel Data. Cambridge, MA: The MIT Press, 2002.

25. Yang, H., Zhang, A. "Effects of high-speed rail and air transport competition on prices, profits and welfare." Transportation Research Part B, 46 (10), 2012, 1322-1333. 


\section{Appendix tables}

Table 1. List of routes.

\begin{tabular}{|c|c|c|c|c|c|}
\hline & Origin & Destination & & Origin & Destination \\
\hline 1 & Bari (BRI) & Milan Linate (LIN) & 35 & Milan Malpensa (MXP) & Palermo (PMO) \\
\hline 2 & Bari (BRI) & Milan Malpensa (MXP) & 36 & Milan Malpensa (MXP) & Rome Fiumicino (FCO) \\
\hline 3 & Bari (BRI) & Milan Orio al Serio (BGY) & 37 & Milan Orio al Serio (BGY) & Bari (BRI) \\
\hline 4 & Bari (BRI) & Rome Ciampino (CIA) & 38 & Milan Orio al Serio (BGY) & Cagliari (CAG) \\
\hline 5 & Bari (BRI) & Rome Fiumicino (FCO) & 39 & Milan Orio al Serio (BGY) & Lamezia Terme (SUF) \\
\hline 6 & Bologna (BLQ) & Bari (BRI) & 40 & Milan Orio al Serio (BGY) & Palermo (PMO) \\
\hline 7 & Bologna (BLQ) & Cagliari (CAG) & 41 & Milan Orio al Serio (BGY) & Pescara (PSR) \\
\hline 8 & Bologna (BLQ) & Palermo (PMO) & 42 & Milan Orio al Serio (BGY) & Rome Ciampino (CIA) \\
\hline 9 & Bologna (BLQ) & Rome Fiumicino (FCO) & 43 & Naples (NAP) & Milan Linate (LIN) \\
\hline 10 & Brindisi (BDS) & Bologna (BLQ) & 44 & Naples (NAP) & Milan Malpensa (MXP) \\
\hline 11 & Brindisi (BDS) & Milan Linate (LIN) & 45 & Naples (NAP) & Rome Fiumicino (FCO) \\
\hline 12 & Brindisi (BDS) & Milan Malpensa (MXP) & 46 & Palermo (PMO) & Bologna (BLQ) \\
\hline 13 & Brindisi (BDS) & Milan Orio al Serio (BGY) & 47 & Palermo (PMO) & Milan Linate (LIN) \\
\hline 14 & Brindisi (BDS) & Rome Ciampino (CIA) & 48 & Palermo (PMO) & Milan Malpensa (MXP) \\
\hline 15 & Brindisi (BDS) & Rome Fiumicino (FCO) & 49 & Palermo (PMO) & Milan Orio al Serio (BGY) \\
\hline 16 & Brindisi (BDS) & Turin (TRN) & 50 & Palermo (PMO) & Rome Fiumicino (FCO) \\
\hline 17 & Lamezia Terme (SUF) & Bologna (BLQ) & 51 & Palermo (PMO) & Turin (TRN) \\
\hline 18 & Lamezia Terme (SUF) & Milan Linate (LIN) & 52 & Pisa (PSA) & Bari (BRI) \\
\hline 19 & Lamezia Terme (SUF) & Milan Malpensa (MXP) & 53 & Reggio Calabria (REG) & Milan Linate (LIN) \\
\hline 20 & Lamezia Terme (SUF) & Milan Orio al Serio (BGY) & 54 & Reggio Calabria (REG) & Rome Fiumicino (FCO) \\
\hline 21 & Lamezia Terme (SUF) & Rome Fiumicino (FCO) & 55 & Reggio Calabria (REG) & Venice (VCE) \\
\hline 22 & Lamezia Terme (SUF) & Turin $(\mathrm{TRN})$ & 56 & Turin $(\mathrm{TRN})$ & Bari (BRI) \\
\hline 23 & Milan Linate (LIN) & Bari (BRI) & 57 & Turin $(\mathrm{TRN})$ & Cagliari (CAG) \\
\hline 24 & Milan Linate (LIN) & Cagliari (CAG) & 58 & Turin (TRN) & Naples (NAP) \\
\hline 25 & Milan Linate (LIN) & Lamezia Terme (SUF) & 59 & Turin $(\mathrm{TRN})$ & Palermo (PMO) \\
\hline 26 & Milan Linate (LIN) & Naples (NAP) & 60 & Turin (TRN) & Rome Fiumicino (FCO) \\
\hline 27 & Milan Linate (LIN) & Palermo (PMO) & 61 & Venice (VCE) & Bari (BRI) \\
\hline 28 & Milan Linate (LIN) & Pescara (PSR) & 62 & Venice (VCE) & Lamezia Terme (SUF) \\
\hline 29 & Milan Linate (LIN) & Reggio Calabria (REG) & 63 & Venice (VCE) & Naples (NAP) \\
\hline 30 & Milan Linate (LIN) & Rome Fiumicino (FCO) & 64 & Verona (VRN) & Bari (BRI) \\
\hline 31 & Milan Malpensa (MXP) & Bari (BRI) & 65 & Verona (VRN) & Cagliari (CAG) \\
\hline 32 & Milan Malpensa (MXP) & Cagliari (CAG) & 66 & Verona (VRN) & Naples (NAP) \\
\hline 33 & Milan Malpensa (MXP) & Lamezia Terme (SUF) & 67 & Verona (VRN) & Palermo (PMO) \\
\hline 34 & Milan Malpensa (MXP) & Naples (NAP) & & & \\
\hline
\end{tabular}

